UCRL-90915

PREPRINT

CONF-850/36--5

\title{
BUOYANT PLUME CALCULATIONS
}

\author{
J. E. Penner \\ L. C. Haselman \\ L. L. Edwards
}

This paper wes prepared for presentation at the

AIAA 23rd Aerospace Sciences Meeting

Reno, Nevada, January 14-17, 1985

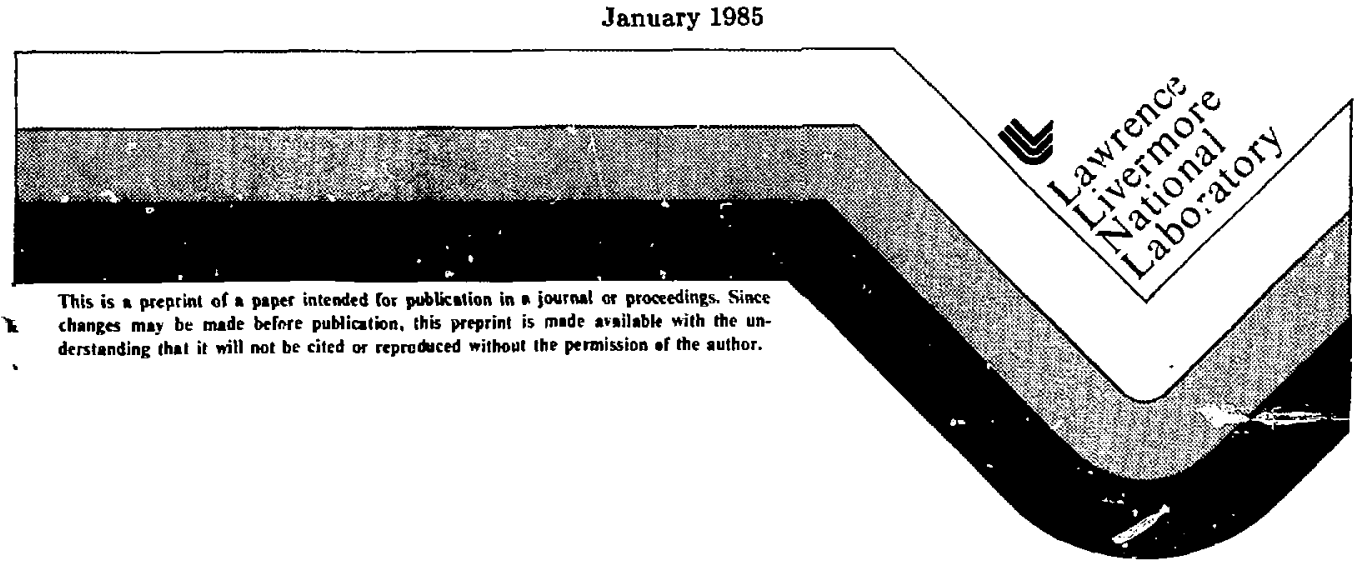

DASTRIBUTIOH OF THIS OBCUMENT IS UHLIMTED 
BUOYANT PLUME CALCULATIONS

\author{
J. E. Penner, L. C. Huselman and L. L. Edwards \\ UCRL- -90 Si5 \\ Lawrence Livermore National Laboratory, University of California \\ Livermore, California 94550
}

\begin{abstract}
Smoke from raging fires produced in the aftermath of a major nuclear exchange hus beon predicter? to cause large decreuses in surface temperatures. However, the extent of the decrease and even '.3. sign of the temyerature change, depend on haw the smoke is distributed with altitude. We present a mudel capable of eveluating the initial distribution of lofted smoke above a massive fire. Calrulations are shown for a two-jinensional slab version of the inodel and a full three-dimensional version. The model has been evaluated by simulating smoke heights for the Hamburg firestorm of 1943 and a smaller scale oil fire which, occurred in Long Beach in 1958. Our plume heights for these fires are compared to those predicted by the classical Morton-Taylo:-Turner thecry for weatly buoyant plumes. We consider the effect of the added buoyancy caused by condensation of water-laden grot:- 1 level air being rartied to high altitude with the convection column as well as the effects of background wind on the calculated smoke plume heights for several fire intensities. We tind that the rise height of the plume depends on the assumed barkground atmospheric condjtions as well as the fire intensity.
\end{abstract}

Little smokc is injected into the stratosphere unless the fire is unusually intense, or atmospheric conditions are more unstable than we have atsumed. For intenst: fires significant amounts of water vapor are condensed raising the possibility of early scavenging of smoke particles by precipitation.

\section{Introduction}

Mary raging fires are expected to be produced in the aftermath of a major nuclear exchange. These fires could cause significant amounts of smoke to be lofted into the atmosphere with possible dramatic climatic ronequences. ${ }^{1-3}$ However, the magnitude of the climate effect depends on, among other things, the amount of smoke produced in the fires, its height of injection, and the exient to which it is scavenged by precipitation formed in the early rising smoke columnn. ${ }^{\text {9-7 }}$

In this paper, we addres the second of these three issues. The atmospheric dy ramics associated with large fires have been studied before. For example, Brode et al. ${ }^{8}$ and Hassig and Rosenblatt ${ }^{9}$ have treated plume dynuslics from large area fires using numerical simulations of the hydrodynamics associated with such fires. Carrier et al. ${ }^{10}$ and Manins ${ }^{11}$ used a semi-analytic approach based on the plume rise theory developed by Morton et al. ${ }^{12}$ All of these studies neglected the effects of the added buoyancy caused by the condensation of water vapor which is frenduced in the fire or carried from ground level to attitude by sre-induced dynanics. Further, these models lave been imited by assumptions of slab or axisymmetric geometries which may be unrealistic, particularly in the caze of background winds.

More recently, $\operatorname{Cotton}^{6}$ has used a cloud-scale hydrodynamic model to study both plume rise and cariy scavenging of smoke. His model is three-dimensional and incluojes a relatively sophisticated treatment of condensation and precipitation. He has atudjed smoke injection heights for a single fire environment: a large arca fire that takes place in high!y unstable background atmospheric r'onditions and at high altitude above sea level.

In this work we extend the above studies by examining separately how the energy release rate of the fire and the background atmospheric conditions influence smoke injection heights. Our theoretical results without condensation or kackground winds will be compared to the nore casily applied semi-anelytic theory of Morton, Taylor, and Turner ${ }^{12}$ es discussed by Carrier et al. ${ }^{10}$ and Manirs, " in order to differentiate the effects of varying entrainment treatment:s. These results will also be compared $t$, obsesvations.

\section{Description of Model}

The model we have used was developed in both a twoand threedimensional form for the purpose of modeling hydrodynamic flows within the internal combustion engine. ${ }^{13}$ It has been applied to the simulation of liquified natural gas (LNG) spills ${ }^{14}$ as well as to explosione of LNG. The model solves the equations of motion for a fully compressible, nonhyirostatic fluid, In addition to equations describing the conservation of energy, mass, and mumentum, species equations for water vapor, condensed water (ice and/or liquid), and a mass-less tracer (smoke) are solved. Previous tests of the model, involving the applications referred tc above, were restricted to spatial scales that are at least a factor of $10 \mathrm{smaller}$ than the applications envisioned here." For this work, we have expanded tise vertical and horizontal extent of the model domain to 20 and $50 \mathrm{~km}$, respectively. For most of our studies, mid-latitude spring/fall background temperatures from the U.S. Standard A tmosphere Supplements ${ }^{15}$ were adopted. This atmosphere has a lapse rate corresponding to $6.2^{\circ} / \mathrm{km}$ in the troposplere which extends to $11.5 \mathrm{dm}$ and is weakly stable under conditions of saturated adiabatic rise.

"The formulation of the finite difference scheme is indifferent to the overall extent of the physichl simulation provided cnough zonal resolution is avaitable. 
Our initial simulations, reported carlier by Penner ${ }^{16}$ and Penner, Haselman, and Porch, ${ }^{17}$ were carried out with a turbulence prescription based on the model developed for small scale applications. In particular, the turbulent viscosity was set equal to

$$
\begin{gathered}
\mu_{\mathrm{t}}=(\Delta)^{2} k_{d}^{2}\left[\left(\frac{\partial u}{\partial y}+\frac{\partial v}{\partial x}\right)^{2}\right. \\
+\left(\frac{\partial w}{\partial x}+\frac{\partial u}{\partial z}\right)^{2}+\left(\frac{\partial u}{\partial y}+\frac{\partial v}{\partial z}\right)^{2} \\
\left.+2\left(\left(\frac{\partial u}{\partial x}\right)^{2}+\left(\frac{\partial v}{\partial y}\right)^{2}+\left(\frac{\partial w}{\partial z}\right)^{2}\right)\right]^{1 / 2} .
\end{gathered}
$$

This formulation, of course, neglects the effect of buoyancy-produced turbulence. ${ }^{18}$ In this work, we have included this effect by writing the turbulent viscosity as

$$
\begin{gathered}
\mu_{t}=(\Delta)^{2}\left\{k _ { d } ^ { 2 } \left\{\left(\frac{\partial u}{\partial y}+\frac{\partial v}{\partial x}\right)^{2}\right.\right. \\
+\left(\frac{\partial v}{\partial x}+\frac{\partial u}{\partial z}\right)^{2}+\left(\frac{\partial w}{\partial y}+\frac{\partial v}{\partial z}\right)^{2} \\
\left.+2\left(\left(\frac{\partial u}{\partial x}\right)^{2}+\left(\begin{array}{c}
\partial v \\
\partial y
\end{array}\right)^{2}+\left(\begin{array}{c}
\partial w \\
\partial z
\end{array}\right)^{2}\right)\right]^{1 / 2} \\
\left.+k_{b}^{2}\left|\frac{\partial}{\partial} \frac{\partial \theta}{\partial z}\right|^{1 / 2}\right\}
\end{gathered}
$$

where

$$
\begin{aligned}
\Delta & =(\Delta x \Delta y \Delta z)^{1 / 3}, \text { is a length scale, } \\
k_{d} & =0.2, \text { is a dimensioi. less constani, } \\
k_{b} & =0.2 \text { if } \partial \theta / \partial z<0, \\
k_{b} & =0.0, \text { if } \exists \theta / \partial z>0, \text { is a dimensionless constant, } \\
\theta & =T_{0}\left(100 c / P_{0}\right)^{R / C_{p}}, \text { is the potential icmperature, } \\
& \text { and } \\
\theta & =980 \mathrm{sm} / \mathrm{s}^{2}, \text { is the acceleration of gravity. }
\end{aligned}
$$

We have found that this added source of turbulence does not significantly affect smoke deposition heights in our model.

\section{Model Testing}

Data with which to test our model for conditions correspording to a very in tense fire are ra.'e. Manins ${ }^{11}$ lists several fires ranging in estimated magnitude from $2 \times 10^{4}$ $\mathrm{MW}$ to $1.7 \times 10^{6} \mathrm{MW}$. As shown below, smoke injection heights are sensitive to the amount of condensation that occurs in the rising, smoke column. Thus, soodel results are sensicive to details of the assumed background atmospheric conditions. For the intense tires of WWII that developed into fircstorms (c.g., Hamburg, Dresden, and Hiroshima), detriled information on background atmospheric corditions is not available. In addition, the reported smoke heights are typically from the incidental reports of WWII pilots and thus poorty known. Nevertheless, these WWII fires represent conditions closest to those we wish to consider here. Therefore, we will explore a simulation ior the Hamburg frestorm as a test of oi: rodel for large, intenge fires.
The Hamburg Firestorm : An Intense Energy Source

In the Hamburg fire, a total arca of ahout $12 \mathrm{~km}^{2}$ with a fuel loading of $157 \mathrm{~kg} / \mathrm{mi}^{2}$ burned in about 6 hours. ${ }^{10}$ The estimated total power output was $1.7 \times 10^{6}$ MW. 10,11,;9 The observed ambient winds were light, less than $4 \mathrm{~m} / \mathrm{s}$ at ground level. The atmospheric lapse rate was reported as $8.8^{\circ} / \mathrm{km}$ up to $3 \mathrm{~km}$ and $1.67^{\mathrm{c}} / \mathrm{km}$ above that level (Brunswig ${ }^{20}$ as quoted by Carrier et al. ${ }^{10}$ ). This ground level lapse rate is close to a dry adiabatic atmospheric lapse rate, but the lapse rate above $5 \mathrm{~km}$ secms unrealistically sinall. Therefore, for test purposes, we adopted the standard atmospheric profile for midlatitusle spring; i ill conditions with a lapse ratc of $6.2 \% \mathrm{kra}$ and no background wind. Tlie atmosphere was assumed to be dry so that no condensation of water vapor took place. Aл energy release rate of $1.7 \times 10^{6} \mathrm{MW}$ was assumed over a circil of radius $2 \mathrm{~km}$.

Our results for smoke injertion heights for the simulated Hamburg firestorm are shown in Figures $1 a$ and 1b. As shown in Figure 1a, for a fully three-dimensional simulation after $1800 \mathrm{~s}$ of simulated fire, the smoke plunc has risen to $12 \mathrm{~km}$ directly above the fire. but drops to about $8 \mathrm{~km}$ as it spreads away from the source. Thus, the smoke from this hire appears to "overshoot" its equilibrium height directly above the fire and return to lower a)titudes downwird. This is a conmonly observed sniure for many of the smaller fires that have been studind in more detail. ${ }^{21}$

The velocity field for this simulation is shown in Figure $1 \mathrm{~b}$. The velocity field confirms that the smoke which is carried to the highest altitudes will he adverted downward as it spreads away from the center of the fire. Thus most of the smoke after 6 hours of burning, will be injected near 8-9 km. These calculated smoke plume heights agree well with the observed values of $9-12 \mathrm{~km}$ as quoled by Marins." Thus, our uodel procedures seem to be verified, to some extenc, for large-scale, intense fre conditions.

\section{Tbe Long Beach Fire: A Less Intense Energy Source}

In contrast to the data available for large fires, examples of smaller fires are easily found. Here we choose to study one ine which took place in Lono Beach in $1958,{ }^{22}$ primarily because it represents the largest fire used to verify the Morton, Taylor, Turner ${ }^{12}$ theory (hereafter referred to es MTT, see discussion below).

For this fire, the sky was clear indicating a dry, nonconvective or stable atmosphere, and satisfying the conditions recessary to properly apply MTT. The smoke plume is described by Davies ${ }^{22}$ as being cone-shaped and 1000 m thick with a top at over $1800 \mathrm{~m}$ as observed $1.6 \mathrm{~km}$ downwind of the fre center. At $48 \mathrm{kIn}$ downstrearn, the smoke plume was observed to be $1800 \mathrm{~m}$ thick with a top near $3,300 \mathrm{~m}$. Atrospheric conditions were such that there was no wind to $1.2 \mathrm{~km}$, and the temperature lapse rate was $6.5^{\circ} / \mathrm{km}$. The heat release rate for this fire was $10,000 \mathrm{MW},{ }^{23}$ The radial extert of the fire was not given.

We simulated this fire using a calm background atmosphere which was assumed to be dry so that no condensation of water vapor occurred. The radius of the circular fire aren was assumed to be $500 \mathrm{~m}$. While this area might be somewhat large, model experiments with a slab con- 


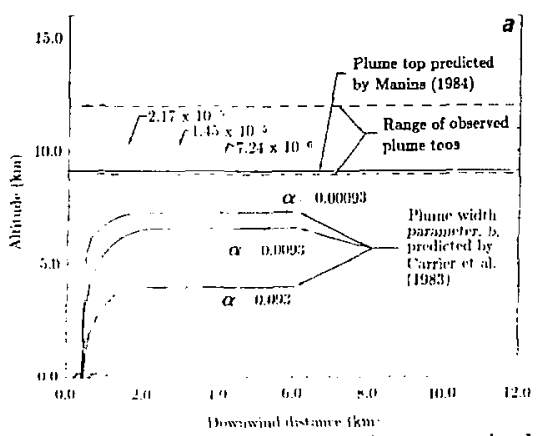

FIGLRE 1a. Smoke mass mixing ratio contours in the $x-z$ plane after $1800 \mathrm{~s}$ for the Harburg firestorm simulation. The geometry of the modal simulation assumed a reflection plane at $s=\mathrm{D}$ and $y=0$, with a constant heat release rate of $1.7 \times 10^{6} \mathrm{MW}$ extending over a circular radius of $2 \mathrm{~km}$. Contour intervals are $1 / 10$ of the snaximum predicted smoke mass mixing ratio, which was $7.24 \times 10^{5} \mathrm{gm} / \mathrm{gm}$. The observed range of plume tops are shown, as well us the predicted top from Manins ${ }^{11}$ and Carrier et al. ${ }^{10}$ The plume width parameter, $b$, calculated by Carrier et al, ${ }^{10}$ extends to infinity at the top of the plume.

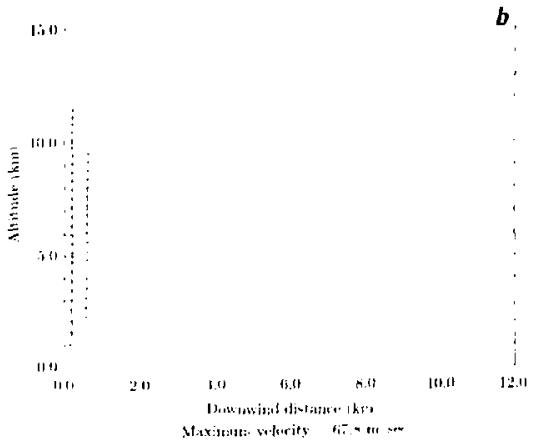

FIGLRE $1 \mathrm{~b}$. Velocity field in the $x-z$ plane after $1800 \mathrm{~s}$ for the Hamburg firestorm simulation. The maximum predicted velocity was $67.8 \mathrm{~m} / \mathrm{s}$. (See caption for Figare 1a.)

figuration showed that the predicted smoke heights downwind of the fire were relatively insensitive to the areal extent of the fire, provided the total energy release rate was fixed. With smaller areal extcnt however, the overshoot near the center of the plume becomes more pronounced.

Smoke mass mixirg ratio contours in the $x-z$ plane for this fire are shown in Figure 2a. The velocity field is shown is Figure $2 \mathrm{~b}$. Our siuulation appears to overestimate smoke heights close to the fire. However, the smoke appears to be spreading out in a bend that is consistent with the snoke column as observed from $48 \mathrm{~km}$ away. The top of the smoke plume is quite consistent with that predicted by Briggs ${ }^{23}$ using MTT (see below).

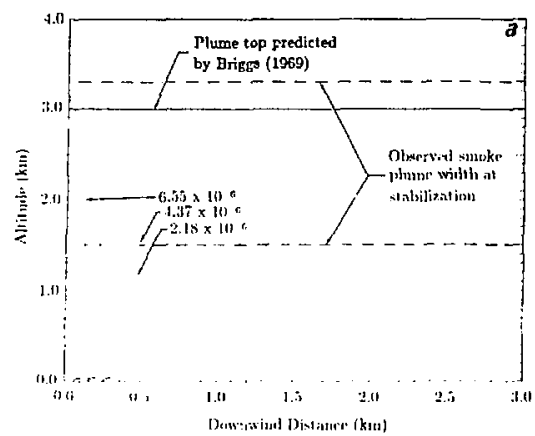

FIGURE 2a. Smoke mass mixing ratio contours in the $x-z$ pline after 3600 \& for the Long Beach fre simulation. The geometry of the model simulation sssumed a reflection plane at $x=0$ and $y=0$, with a constant heat release rate of $10^{4} \mathrm{MW}$ extending orer a circular region with a radius of $500 \mathrm{~m}$. Contour intervals are $1 / 10$ of the maximum predicted smoke mass mixing ratio, which was $2.18 \times 10^{-5}$ $\mathrm{gm} / \mathrm{gm}$. The observed width and altitude of the smoke plume as well as the plume top predicted by Briggs ${ }^{23}$ are also shown.

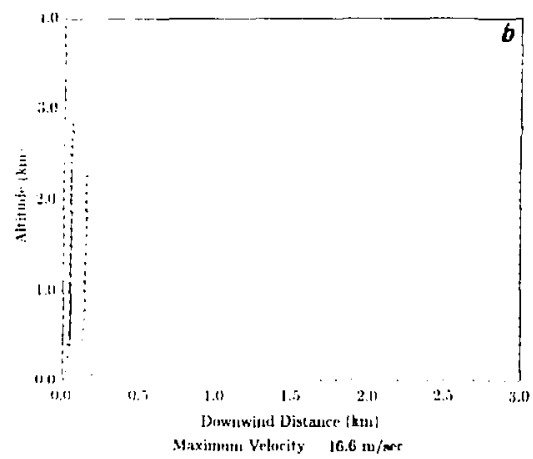

Fuc;t'RE 2l). Velocity field in the $r-y$ plane after 36005 for the Long Beach fire sinulation. The maximum pre-

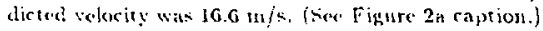

We conclude that our model provides a good description of smoke injection heights for a range of fire intensities, at !east under dry, calm conditions whire little condensation takes piace. We describe below how water condensation afiets smoke heigits.

\section{Comparison of Model Results to the Morton-Taylor-Turner Semi-Analytic Solution}

Both of the fires described above have been studied using the Morton-Taylor-Turner ${ }^{12}$ plume rise theory (MTT). Tisis is a semi-analytic approach that is applicable in etably etratified atmospheric conditions. Morton et al. develop equatio:s for an axisymmetric system assum. ing $t$ radial form for the smoke plume that is similar for 
all heights. This reduces the system of equations to three (species equations for water are not considered):

$$
\begin{gathered}
\frac{d}{d z}\left(b^{2} \bar{w}\right)=2 \alpha b \bar{w} \\
\frac{d}{d z}\left(b^{2} w^{2}\right)=b^{2} g^{\prime} \\
\frac{d}{d z}\left(b^{2} w g^{\prime}\right)=-b^{2} w N^{2}(z)
\end{gathered}
$$

where

$$
\begin{aligned}
b & =\text { the effective radias of the plume } \\
\bar{w} & =\text { the average vertical velocity in the plume } \\
g^{t} & =g\left(\rho_{0}-\rho\right) / \rho_{1} \\
N^{2} & =\left(-g / \rho_{1}\right)\left(d \rho_{0} / d z\right) \\
\rho & =\text { density in plume } \\
\rho_{0} & =\text { arabient density } \\
\rho_{1} & =\text { reference density at the surface. }
\end{aligned}
$$

The first equation describes conservation of volume (or mass), the second, conservation of momentum, and the third, conservation of buoyancy. Further assumptions include the Boussinesq approximetion (i.e., perturbations to density are small except as they affeci buoyancy), and the assurnption that the rate of entrainment of aubient air at height $z$ is proportional to a characteristic velocity at that height, with proportionality factcr $\alpha$. These equations were transformed to a nondimensional form and then solved assuming a virtual point source at the nondimensional height $z_{1}=0.0$.

The MTT theory has been applied with few changes to large area fires by Manists. ${ }^{\text {is }}$ He calculates, for example, the plume height for Hamburg as $9.2 \mathrm{~km}$ assuming an entrainment copficient of 6.132. However, Manins treats the approximate $12 \mathrm{~km}^{2}$ fire source arca as point at the surface, thereby neglecting the reguirement of Morton et al. to determine a viztual source below the gurface to account for fire area. Manins compares his model to a variety of large fires with rather good agreement. However, given the poor data usually available for large fires, and Manins' apparent disregard for the borizontal cxtent of the fire, this agreement may be fortuitous.

Carrier et al. ${ }^{10}$ also applied the Morton-Taylor-Tusner theory to large area fires. They do, in fact, take account of the need to locate a virtual source below the surface to allow for the areal extent of the fire. But they then find that the Hamburg fire plume reaches only $4 \mathrm{~km}$ using the ambient entrainment coefficient of 0.093 , considered appropriate for smaller fires. Carrier et al. therefore argue that entrainment rates are reduced due to a fire convection column whirl. They include equations expressing the conservation of angular and radial momentum in order to quantify the reduced entrainment expected in a spinning fire whirl. Unfortunately even this treatment is unsatis fying because both the area of the surface region, used to locate the virtual point source, and the entrainment coefficient can be adjusted until obervations are rratched.

Cur calculated smoke heights for the Hamburg fire are compared to ohservations and those predicted by Carrier et al. and Manins in Figure 1a. The smoke heights for the Irong Bezch fire as predicted by Brigbs ${ }^{23}$ are compared in Figure 2a.
Our results for Long Beach are similar to those of Briggs. For Hamburg, our results compare well to those predicted by Manıns, using ambient entrainment rates $(a=0.132)$ and neglecting the areal extent of the fire or to those of Carrier et al. using reduced entrainment ratey.

As mentioned above, our slab model experiments for the Long Beach firc showed little sensitivity to the areal extent of the fire if the total energy source was fixed." This observation tends to support Manins' application of the Morton-Taylor-Turner theory which neglects the fire area but requires no adjustroent of the entrainment rate. Howcver, more study is needed to confirm this.

\section{Results of Simulations for Large Area Fires}

Previous sections have discussed the application of our model to both large (Hamburg) and small (Long Beach) fires. For both of these simulations, condensation of water vapor and background wind speeds were regligible. In this section, we explore the sensitivity of our model to these effects. Most of the calculations which follow were performed with a two-dimensional slab configuration, but we show a few comparisons to full three-dimensional simulations.

Figures 3-5 exuminc haw smoke deposition heights change as background wind speeds and condensation of water vapor is added. Figures a, b and $c$ in each case rorrespond to results computed with a slab configuration, while $d$ corresponds to a full threc-dimensional simulation.

Three fire intensity sources are consjdered: $B .9 \times 10^{4}$ $\mathrm{W} / \mathrm{m}^{2}, 1.4 \times 10^{4} \mathrm{~W} / \mathrm{m}^{2}$, and $2.3 \times 10^{3} \mathrm{~W} / \mathrm{m}^{2}$. Assuming a heat release rate characteristic of buming wood, namely $2 \times 10^{4} \mathrm{j} / \mathrm{g}$, the first intensity corresponds to burning a total fuel load of $10 \mathrm{~g} / \mathrm{cm}^{2}$ in about 6 hours, the second corresponds to burning $3 \mathrm{~g} / \mathrm{cm}^{2}$ in about 12 hours, and the third corresponds to burning $0.5 \mathrm{~g} / \mathrm{cm}^{2}$ in about 12 hours. These three fuel loadings represent the three norninal cases considered by Turco et al. ${ }^{2}$ for city centers, suburban regions, and forested areas, respectively.

Emission rates for smoke ware assumed to be $3 \%$ of the fuel consumption rate. In each calculation the smoke source region extended from $-5 \mathrm{~km}$ to $+5 \mathrm{~km}$ about the center. For all cases the amhient teraperature profile is thai for the spring/fall midlatitude atrosphere. ${ }^{15}$

I. Figures a and b of each set only half the domain is shown since the simulation is symmetric about the origin. In Figures $c$ and $d_{1}$ a background wind was assumed present which carried the smoke to the downwind side of the source region The scale on the abscissa of these figures has heen shifted accordingly.

In Figure 3a dry, calm conditions were assumed so that no background wind was present and water vapor did not ccndense. In Figure $3 \mathrm{~b}$ the global average relative humidity profile from Manabe and Wetharald ${ }^{24}$ was allowed to be caryicd aloft in the convection column. As vapor condenses at high altitude latent heat is released and drives the smoke plume higher.

\footnotetext{
-We varied the areal extent of the Long Beach fire by factors of $1 / 4$ and 4 .
} 


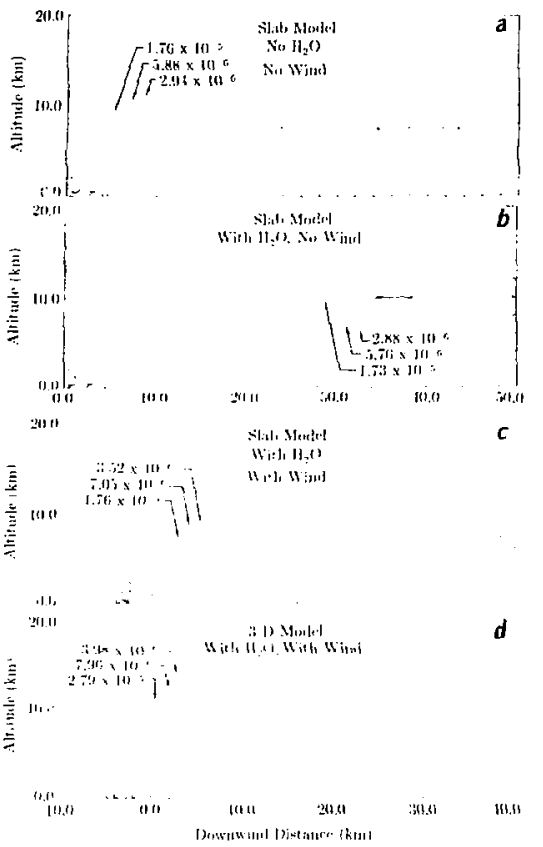

FIGURE 3. Smoke mass mixing ratio contours in the $x-z$ plane after $3600 \mathrm{~s}$ from a $5 \mathrm{~km}$ radius fire with a heat release rate of $8.9 \times 10^{4} \mathrm{~W} / \mathrm{m}^{2}$. Figures $\mathrm{a}, \mathrm{b}$, and $c$ were produced using a slab-geometry model. Figure d represents a calculation from a full three-dimensional simulation. Contour intervals for each figure are $t / 10$ of the meximum predicted mass mixing ratios which were $2.94 \times 10^{-5}, 2.88 \times 10^{-5}, 3.52 \times 10^{-5}$, and $3.98 \times 1 \mathrm{C}^{-5}$ $\mathrm{gm} / \mathrm{gm}$ for Figures a-d, respectively. (See text for explanation.)

In Figures $3 c$ and $3 d$ average backgrouud winds (sce Figure 6) were assumed present before and during the fire simulation. ${ }^{25}$ These background winds change the developing smoke convertion field and carsy away the smoke that reaches the highest altitudes. However, as shown by comparison of Figures $3 c$ and $3 d$, in the slab configuration. horizontal velocities are stronger and upward momentum is more easily damped than in the full three-dimensional simulation (compare the velocity fields shown in Figures $7 \mathrm{a}$ and $\mathrm{rb}$ ). Thus, the smoke does not reach as high an altitude over the fire source area in the slab case as compared to the more realistic three-dimensional case.

For this high intensity source the amount of water vapor which condenses is similar in both the two- and three-dimensional cases (see Figures $8 \mathrm{a}$ and $8 \mathrm{~b}$ as well as the discussion below).

For the smaller intensity sources the effect of the latent heat of condensation is larger when no wind is present (compare Figures $4 a$ and $4 b$ and Figures $5 a$ and $5 b$ ). However, a background wind is able to more effectively reduce

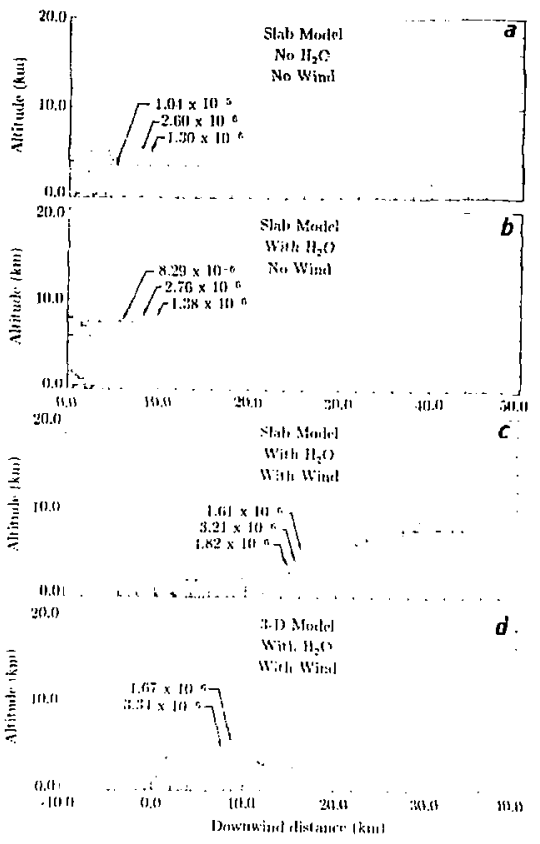

FJGURE 4. Smoke mass mixing ratio contours in the $x-z$ plane after $3600 \mathrm{~s}$ from a $5 \mathrm{~km}$ radius firc with a heat release rate of $1.4 \times 10^{4} \mathrm{~W} / \mathrm{m}^{2}$. Figures $\mathrm{a}, \mathrm{b}$, and c were produced using a slab geonetry model. Figure d represents a calculation from a full three-dimensional simulation. Contour intervals for each figure are $1 / 10$ of the maximum predicted Irass mixing ratios which were $1.30 \times 10^{-5}, 1.38 \times 10^{-5}, 1.61 \times 10^{-5}$, and $1.67 \times 10^{-5}$ $\mathrm{gm} / \mathrm{gm}$ for Figures a-d, respertively. (See text for explanation.)

the injection he ight of the smoke for low compared to high intensity sources.

In Figure 4c (compared to $4 \mathrm{a}$ ) the smoke is apparently lofted to higher altitudes as significant amounts of water condenses downwind of the fre. This efect is not present in the three-dimensional simulation (Figure $4 d$ ), because much less water condenses (compare Figures $B c$ and $8 d$ ). This is consistent with the tendency of the slab model to overestimate horizontal momentum and underpredict the amount of "overshoot" associated with any given fire (see for example, Figure 7). Thus, for this fire, in the slab model, the water vapor which is lofted with the initial plume remains at higher altitude and is more easily condensed. This adds buoyancy downwind of the fire, which lofts the smoke even higher.

Figures 9, 10 and 11 show the horizontally integrated smoke density within the model domain corresponding to each configuration as a function of alnitude for the four cases and three fire intensities considered above. Apparently only a small fraction of the total generated smoke 


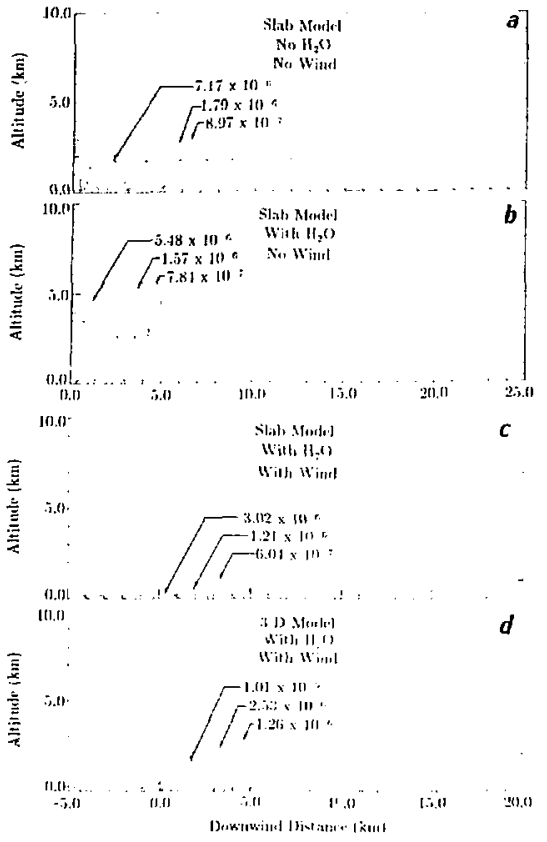

FIGURE 5. Smoke mass mixing ratio contours in the $x-z$ plane after $7200 \mathrm{~s}$ from a $5 \mathrm{~km}$ radius fire with a heat release rate of $2.3 \times 10^{3} \mathrm{~W} / \mathrm{m}^{2}$. Figures $\mathrm{a}, \mathrm{b}$, and c were produced using a slab geometry model. Figuie $\mathrm{d}$ represents a calculation from a full three-dimensional simulation. Contour intervals for each tigure are ${ }^{1} / 10$ of the maximum predicted mass mixing ratios which were $8.97 \times 10^{-6}, 7.84 \times 10^{-6}, 6.04 \times 10^{-6}$, and $1.26 \times 10^{-5}$, for Figures a-d, respectively (see text).

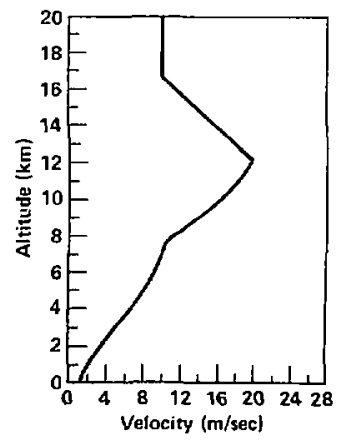

FIGURE 6, Asgumed average backgrourd wind speeds used in the calculations shown in parts $c$ and $d$ of Figures 3-5. These winds are the average of 10 years of radiosonde data of the longitudinal wind at $45^{\circ} \mathrm{N}$ as presented by Oort. ${ }^{25}$

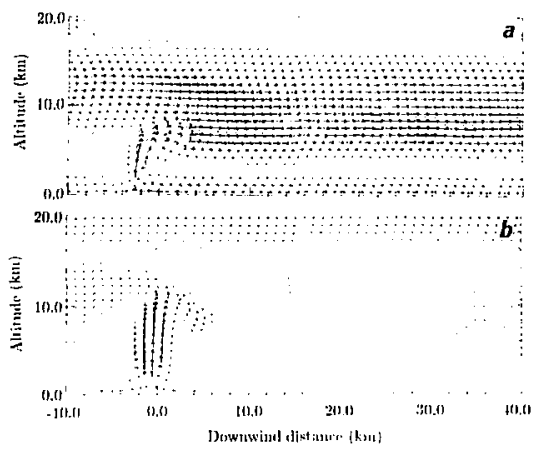

FIGURE 7. Velocity field from the slab model simulation (a) and the full three-dimensional simulation (b) of a 5 $\mathrm{km}$ radius fire with heat release rate of $8.9 \times 10^{4} \mathrm{~W} / \mathrm{m}^{2}$. Figures $a$ and $b$ correspond to the smoke mass mixing ratio contours shown in Figures $3 c$ and $3 d$, respectively.

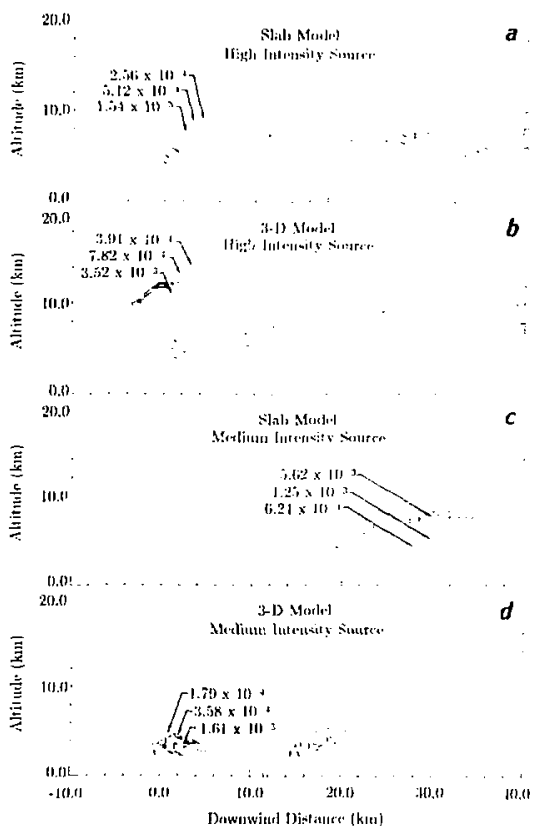

FIGURE 8. Mass mixing tatio contours of condensed water. Figures a-b compare the patterns and amounts of condensed water from the slab model and threedimensional model for a fire of source strength $8.9 \times 10^{4}$ $\mathrm{W} / \mathrm{m}^{2}$. Figures $\mathrm{c}-\mathrm{d}$ compare a similar calculation for a fire of source strength $1.4 \times 10^{1} \mathrm{~W} / \mathrm{m}^{2}$. Contol: intervals for each fgure are $1 / 10$ of the maximum predicted mixing ratios which were $2.56 \times 10^{-3}, 3.91 \times 10^{-3}, 6.24 \times 10^{-3}$, and $1.79 \times 10^{-3} \mathrm{gm} / \mathrm{gm}$ for Figures a-d, respectively. 


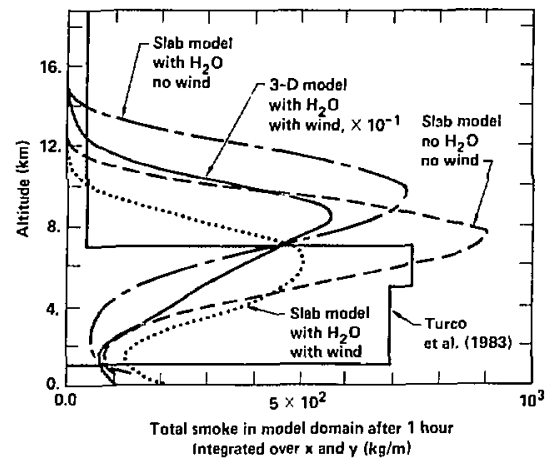

FIGURE 9. Total integrated smoke in model domain as a function of altitude after 1 hour for a high intensity fire of source strength $8.0 \times 10^{4} \mathrm{~W} / \mathrm{m}^{2}$. Results are shown for the four simulations described in Figures 3a-d, as well as for the average vertical profile of smoke assumed by Turco et al. ${ }^{2}$ Turco et al.'s profile extends up to $19 \mathrm{~km}$.

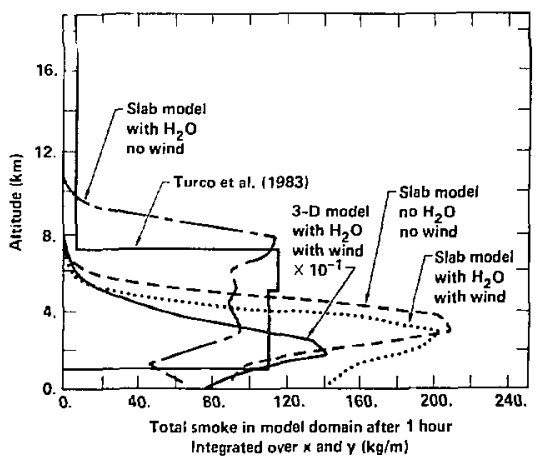

FIGURE 10. Total integrated smoke in model drmain as a function of altitude after 1 hour for a medium intensity fire of source strength $1.4 \times 10^{4} \mathrm{~W} / \mathrm{m}^{2}$. Results are shown for the four simulations described in Figures $4 a-d$, as well as for the average vertical prohle of smoke astumed by Turco et al. ${ }^{2}$ Turco et al.'s profile extends up to $19 \mathrm{~km}$.

reaches and remains at the highest altitudes. Depending on the background atmospheric conditions, most of the sinoke is lofted to between $6-10 \mathrm{~km}$ for the high intensity case, between $2-8 \mathrm{~km}$ for the raedium intensity case and below $3 \mathrm{~km}$ for the low intensity case.

The smoke injection patterns assumed by Turco et al. ${ }^{2}$ are also included in Figures $9-11$. Their assumed lowaltitude smoke deposition heights correspond to a reasonable combination of the low and mid-intensity fire sources, However, even our largest intensity fire lofted little smoke to the stratosphere. (The tropopause is at $11.5 \mathrm{~km}$ in our model.) Under calm conditions, for a high intensity fice, if water vapor condenses, it may cause penetration of the tropopauge by some of the smoke. But, in this case, the

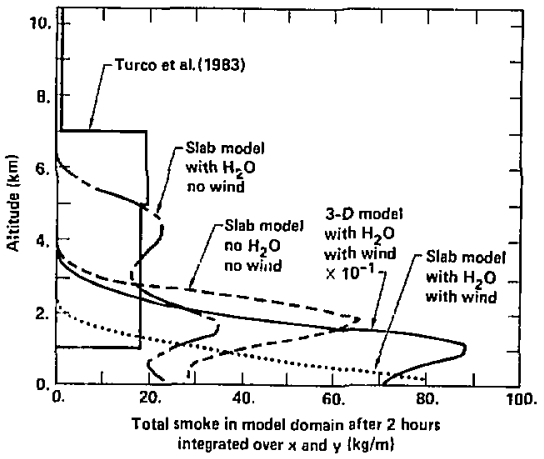

FIGURE 11. Total integrated smoke in model domain as a function of altitude after 2 hours for a low intensity fire of source strength $2.3 \times 10^{3} \mathrm{~W} / \mathrm{m}^{2}$. Results are shown for the four simulations described in Figures $5 \mathrm{a}-\mathrm{d}$, as well as for the average vertical profile of smoke assumed by Turco et al. ${ }^{2}$ Turco et al.'s profile extends up to $19 \mathrm{~km}$.

large amount of condensed water could also act to rapidly remove smoke via precipitation scavergirg.

\section{Conclusion}

We have used a two- and three-dimensional hydrodynamic model to examine smoke injection heights above large-area fires. The height of smoke injection depends critically on

1. the intensity of the heat relense rate,

2. the stability of the background atmosphere,

3. the amount of water vapor present in the background atmosphere (and therefore its tendency to condense), and

4. the background wind speeds.

For average conditions in northern midlatitude regions we predict smoke lofting to heights that are consjstent with the bulk of the smoke distribution assumed by Turco et al. ${ }^{2}$ for nominal fire source intensities of $1.4 \times 10^{4}$ and $2.3 \times 10^{3} \mathrm{~W} / \mathrm{m}^{2}$. However, in contrast to their assumptions, little smoke is injected into the stratosphere even for a very interse fire.

The smok? injection heights reported here are preliminary since precipitation scavenging processes have $\pi \cdot s$ been included. Furthermore, processes which may alter smole injeztion heights on time scales between those appropriate to the plume scales considered here and those appropriate to ihe initiation of global scale climate simulations $2,4, *$ need to bisc be addressed. These processes include, for eximple, coagulation of smoke particles, swelling due to interaction with water vapor, and heating and dynamics associuted with absorption of solar energy by the smoke.

For these simulations, we have not included the source of water vapor due to fuel burning ( 1 gram of water/zram of fue! burned). We ccnjecture that this source could add as much as $25 \%$ more condensed water to the 
system for the high intensity case. Of course, there would be enhanced buoyancy due to the added latent heat of condensation, but we estimate that the plume top would be changed by at most $0.5 \mathrm{~km}$.

The total smoke and condensed water in our threedimensional simulations are summarized in Table 1. Clearly for a high intensity source, enough water is condensed to remove most of the smoke before it spreads to global scales. However, the clouds formed may not precipitate if "overseeding" occurs. The clouds formed above our higher intensity fires for average conditions contain more than $1 \mathrm{gram}$ of condensed water per cubic meter of air, i.e., more than the annount generally assumed necessary -to jnitiate precipitation in the arabient atmosphere. Whether these clouds would actually rain and remove much of the swoke at early times depesiss on the hygroscopic character of the smoke particles, how effectively the particles act as cloud condensation nuclei, as well as other poorly understood and, consequently, poorly modeled processes. ${ }^{6}, 7_{i} 60$ Detailed microphysical models of the interaction of smoke particles with themselves and with water (vapor, liquid, ice) are needed to examine these critical issues.

TABLE 1. Total smoke and condensed $\mathrm{H}_{2} \mathrm{O}$ in threedimensional model domain.

\begin{tabular}{cccc}
\hline $\begin{array}{c}\text { Source } \\
\text { strength } \\
\left(\mathrm{W} / \mathrm{m}^{2}\right)\end{array}$ & $\begin{array}{c}\text { Time } \\
\text { (hours) }\end{array}$ & $\begin{array}{c}\text { Smoke } \\
\text { (tons) }\end{array}$ & $\begin{array}{c}\text { Condensed } \\
\mathrm{H}_{2} \mathrm{O} \\
\text { (tons) }\end{array}$ \\
\hline $8.9 \times 10^{4}$ & 1.0 & $3.55 \times 10^{4}$ & $4.56 \times 10^{6}$ \\
$1.4 \times 10^{4}$ & 1.0 & $5.08 \times 10^{3}$ & $6.30 \times 10^{4}$ \\
$2.3 \times 10^{3}$ & 2.0 & $1.81 \times 10^{3}$ & $1.98 \times 10^{2}$ \\
\hline
\end{tabular}

\section{Ackrowledgments}

This work was performed under the auspices of the U.S. Department of Energy by the Lawrence Livermore National Laboratory under contract No. W-7405-Eng-48. Partial support for this work came from the Defense Nuclear Agency.

\section{Referencen}

1. P.J. Crutzen and J.W. Birks, 1982, "The Atmosphere After Nuclear War: Twilight at Noon," Ambio, 11 , 114-125.

2. R.P. Turco, O.B. Toon, T. Ackerman, J.B. Pollack, and C. Segan, 1983, "Nuclear Winter: Global Consequences of Multiple Nuclear Explosions," Science, 222, 1283-i282.

3. P.J. Crutzen, C. Bruhl, and I.E. Galbally, 1984, "Atmospheric Effects from Post-Nuclear Fires," Climatic Change, in press.

4. M.C. MacCracken and J.J. Valton, 1984, "The Efferts of Interactive Transport and Scavenging of Snoke on the Celculeted Tempcratuse Change Resulting from Large Amounts of Smoke," in Proceedings of the Third Conference on Climate Variations and Symposium on Conternparary Climate 1850-2100, American Meteorological Society, January 7-11, 1985, Los Aлgeles, CA.
5. V. Ramaswamy and J.T. Kiehl, 1984, "Sensitivities of the Radiative Forcing Due to Large Loadings of Smoke and Dust Aerosols," submitted to J. Geophys. Res.

6. W.R. Cotton, 1984, "A Simulation of Cumulonimbus Response to a Large Firestorm-Implication to a $\mathrm{Nu}$ clear Winter, " submitted to American Scientist.

7. E. Teller, 1984, "Widespread After Effects of Nuclear War," commentary, Nature, $910,621624$.

8. H.L. Brode, D.A. Larson, and R.D. Small, 1983, "Hydrocode Studies of Flows Generated by Large Area Fires," in Proceedings of the $1 t^{\text {th }}$ Asilomar Conference on Fire und Blast Effecto of Nuclear Weapons, May 30-June 3, 1983, Pacific Grove, CA., 48-53.

9. P.J. Hassig and M. Rosenblatt, 1983, "Firestorm Formation and Environment Chracteristics After a Large-Yield Nuclear Burst, ${ }^{n}$ in Proceedings of the $17^{\text {th }}$ Asilomar Conjerence on Fise and Blart EJecte of Nuelear Weapors, May 30-June 3, 1083, Pacific Grove, CA, 54-59.

10. G.F. Carrier, F.E. Fendell, and P.s. Feldman, 1983 , "Firestorms," in Fire Dynamics and Heat Transler, HTD-Vol, 25, 55-64.

11. P.C. Manins, 1984, "Cloud Heights and Stratospheric Injection Resul $1 \mathrm{~g}$ from a Thermonuclear War, ${ }^{\text {" mun- }}$ uscript distributed by SCOPE.

12. B.R. Morton, G. Taylor, and J.S. Turner, 1956, "Turbulent Gravitational Convectior, from Maintained and Instantaneous Sources," Proc. Roy. Soc. London, Series $A, 294,1 .-23$.

13. L.C. Haselman, 1980, "TDC-A Computer Code for Calculating Chemically-Fleacting Hydrodynamic Flows in Two Dimensions," tawrence Livermore $\mathrm{Na}$ tional Laboratory Report UCRL-52931.

14. L.C. Haselnan, 1980, "Effe:t of Humidity on the Energy Budget of a Liquified Natural Gas (LNG) Vapor Cloud," Lawrence Livermore National Laboratory Report UCID-18539.

15. U.S. Stondard Atmosphere Supplements, 1966, U.S. Government Printing Office, Washington, DC, 20402, 289 pp.

16. J.E. Penner, 1984, "Smoke Inputs to Climate Modele: Optical Froperties and Height Diatribution," presented at the International Seminar on Nuclear War, August 19-24, 1984, Erice, Italy.

17. J.E. Penner, L.C. Haselman, and W.M. Porch, 1984, "Coagulation and Buoyant Plume Calculations," presented at the Confelence on Large Scale Fire Phenomenology, Septernber 1013,1984 , Gaithersburg, MD.

18. P. Tag, F. Kiurray, end L.R. Koenig, 1979, “A Comparison of Several Forms of Eddy Viscosity Parameterization in a Two-Dimensional Cloud Model, $" J$. Appl. Meteoro., 18, 1424-1441.

19. C.H.V, Ebert, 1963, "The Meteorological Factor in the Hawburg Fire Storm," Weatherwise, April, 7075.

20. H. Brunswig, 1981, "Feurs Turm Über Hamburg," Motorbuch, Stuttgart, Germany. 
21. J.S. Turner, 1973, Buoyancy Effects in Fluids, Cambridge University Press, 376 pp.

22. R.W. Davies, 1959, "Large Scale Diffusion from an Oil Fire," Adv. Geophys., 6, 413-415.

23. G.A. Briggs, 1869, Plume Rise, U.5. Atomic Energy Commiasion Critical Review Series, 81 pp.

24. S. Manabe and R.T. Wetherald, 1967, "Thermal Equilibrium of the Atmosphere with a Given Distribution of Relative Hunidity," J. Atmo8. Sci, 24, 241259.

25. A.H. Oort, 1983, "Global Atmospheric Circulation Statistics, 1958-1973," NOAA Professional Paper 14, U.S. Government Frinting Office, Washington, $D C$.

26. C.R. Molenkamp, 1980, «Numerical Simulation of Self-Induced Rainout Using a Dynamic/Convective Cloud Model," in Proceedings of the VIII International Conference on Cloud Physics, ClermontFerrand, France, July 15-19, 1980. 